\title{
Effect of dietary cholesterol on plasma cholesterol concentration in subjects following reduced fat, high fibre diet
}

\author{
JACQUELINE EDINGTON, MOIRA GEEKIE, ROBIN CARTER, LISA BENFIELD, \\ KAREN FISHER, MADELEINE BALL, JIM MANN
}

\begin{abstract}
One hundred and sixty eight subjects participated in a randomised crossover study to determine whether halving or doubling the present dietary cholesterol intake from eggs had any influence on blood cholesterol concentration in people following current dietary recommendations. During the first eight weeks all participants were advised to follow a reduced fat diet $(26 \%$ total energy for hyperlipidaemic patients, $35 \%$ total energy for normolipidaemic volunteers) with an increased ratio of polyunsaturated to saturated fatty acids. This background diet was continued throughout the 16 week experimental period, during which participants ate either two or seven eggs a week. A small but significant increase in total cholesterol was seen after four weeks in the group eating seven eggs a week compared with that in the group eating two eggs a week, but this was no longer apparent after eight weeks.

Previous studies suggesting that dietary cholesterol has a greater effect on the serum cholesteról concentration either have been carried out against a background of a higher fat intake or have contrasted extreme cholesterol intakes. A further reduction in dietary cholesterol seems to be unnecessary in those people who have already reduced their intake of saturated fat and increased the ratio of polyunsaturated to saturated fatty acids and fibre rich carbohydrate.
\end{abstract}

\footnotetext{
Department of Community Medicine and General Practice and Diabetes Research Laboratories, Radcliffe Infirmary, Oxford

JACQUELINE EDINGTON, BSC, SRD, research dietitian MOIRA GEEKIE, SRD, research dietitian

ROBIN CARTER, MIST, senior medical laboratory scientific officer LISA BENFIELD, junior medical laboratory scientific officer KAREN FISHER, HNC, medical laboratory scientific officer JIM MANN, DM, PHD, university lecturer and honorary consultant physician

Department of Clinical Biochemistry, John Radcliffe Hospital, Oxford MADELEINE BALL, MB, MRCP, clinical lecturer and senior registrar

Correspondence to: Jacqueline Edington.
}

\section{Introduction}

The results of several investigations have suggested that dietary cholesterol has an important influence on plasma cholesterol concentration,,$^{1-3}$ to an extent that can be predicted with the Keys formula. ${ }^{4}$ Two research groups have found a few subjects whose plasma cholesterol concentration is particularly sensitive to increases in dietary cholesterol. ${ }^{5.7}$ Some authorities advise a specific reduction in dietary cholesterol because of the suggestion that the mean plasma cholesterol concentration of the population would be decreased by greatly reducing the dietary intake of the few people who are hyperresponders. ${ }^{8}$ ?

Several features of previous studies, however, limit the generalisations that can be made from their results. Most have been short, ${ }^{10}$ and several have included small numbers of participants. ${ }^{2}{ }^{10}$ " Other investigations have contrasted quantities of cholesterol that are unlikely to be consumed in the long term. ${ }^{3}{ }^{12}{ }^{13}$ Finally, the background diet has been high in saturated fat, in contrast with the diet low in saturated fat that is currently recommended. ${ }^{\text {it }}$ is

Eggs are a major source of dietary cholesterol. We therefore examined the effects of halving and almost doubling the present national average intake of four eggs a week ${ }^{16}$ in a large group of volunteers who were following a low fat, high fibre diet to help to determine whether a reduction in dietary cholesterol should be included in dietary recommendations.

\section{Subjects and methods}

\section{SUBJECTS}

Two groups of participants were studied. One hundred and ninety four healthy volunteers were recruited by an advertisement in a local newspaper. Thirty five of these respondents were not included in the study because they had an intercurrent illness, were found to be hyperlipidaemic, or felt unable to participate once the details of the study had been explained. Twenty four other participants withdrew during the study because they felt unable to stick to the dietary protocol, and their data were excluded. One hundred and thirty five volunteers completed the study ( 27 men, 108 women).

Thirty three patients ( 20 men, 13 women) who had hyperlipidaemia and who attended the lipid clinic at John Radcliffe Hospital were also studied. 
The diagnoses were: familial hypercholesterolaemia (five men, seven women), hypertriglyceridaemia (four men, one woman), familial combined hyperlipidaemia (three men), and common hypercholesterolaemia (eight men, five women). All had relatively stable plasma lipid concentrations before the study, and drugs for treating hyperlipidaemia were unchanged during the study. The participants gave informed consent, and the study design was approved by the central Oxford research ethics committee.

\section{EXPERIMENTAL DESIGN AND DIETS}

The figure shows the experimental design. The study lasted for 24 weeks and comprised an eight week run in period followed by two further eight week experimental periods. During the run in period diets were individually prescribed according to participants' energy requirements. The aim during

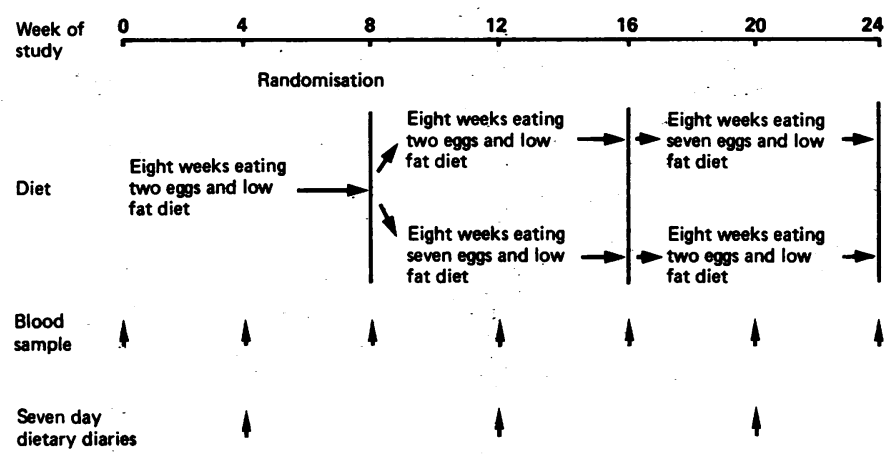

Design of experiment.

this period was to achieve a stable body weight on a low fat, high fibre diet that would be the background diet for the entire study. Table I shows the distribution of various nutrients in a $1500 \mathrm{kcal}$ diet, the most commonly prescribed energy level. Individual energy requirements ranged from 1000 $\mathrm{kcal}$ to $3000 \mathrm{kcal}$, and nutrients were adjusted accordingly. The diets for the hyperlipidaemic patients were lower in total fat content and had a higher ratio of polyunsaturated fatty acids to saturated fatty acids than those recommended for the healthy volunteers, which were based on the recommendations of the panel of the Committee on the Medical Aspects of Food Policy ${ }^{17}$ but had a slightly higher ratio of polyunsaturated to saturated fatty acids.

After the run in period, during which all participants ate up to two eggs a week, subjects were randomised into two groups. The first group continued to eat two eggs a week, and the seond increased its egg consumption to seven eggs a week. In the experimental diet one egg was substituted for one ounce of medium fat meat, or equivalent protein exchange, to keep the diet isocaloric and saturated fat intake constant. After eight weeks the two groups crossed over. The background diet remained unchanged throughout the 16 week experimental period.

Dietary advice was reinforced at regular intervals throughout the study. Each participant completed three dietary diaries, one beginning at week 4, one at week 12 , and one at week 20 that is, halfway through each dietary period. These were used as one method of assessing dietary compliance. Analysis of these dietary diaries showed that the volunteers followed closely the dietary advice. In particular, participants found that modifying their egg intake was easy, and compliance with this aspect of the advice was excellent.

The mean age of all 168 participants was 45 (range 22 to 69). The mean (SD) body mass index at the beginning of the study was $24 \cdot 8(3 \cdot 2)$ but decreased to $23.9(3.1)$ (range $18 \cdot 2-34 \cdot 7)$ at the end of the run in period $(p<0 \cdot 05)$. The body weights did not change during the experimental period.

\section{LABORATORY MEASUREMENTS}

Blood samples from fasted subjects were taken at recruitment and at eve four weeks throughout the study. The total cholesterol concentration and the cholesterol concentration in the lipoprotein subfractions were measured with a Technicon AutoAnalyzer II. The total cholesterol concentration w(19) measured enzymatically in diluted plasma with kits obtained from Boehringer..$^{18-20}$ Very low density lipoprotein cholesterol and low density lipoprotein cholesterol were precipitated with the heparin mangane method, leaving high density lipoprotein cholesterol in solution to measured. ${ }^{21}$ In a second aliquot very low density lipoprotein cholesterol was precipitated with sodium dodecyl sulphate, leaving high density lipoprotein cholesterol and low density lipoprotein cholesterol in solution. ${ }^{22}$ Thre quantities of cholesterol in the various subfractions were then calculated by subtraction. The plasma triglyceride concentration was measured with enzymatic method ${ }^{23}$ with a CoBas-Bio centrifugal analyser manufactured Roche Diagnostics.

In addition to the dietary diaries another indication of compliance with the diet modified in fat was obtained by measuring the fatty acid composition serum triglyceride ${ }^{24}$ at the beginning of weeks 0,12 , and 24 . The triglyceride fraction was identified by thin layer chromatography, and the methyl esters of the fatty acids were measured by gas liquid chromatography. There wasta sustained increase in the proportion of linoleic acid (C18:2), indication compliance with the background dietary advice. Persuading the subjects wo change their usual diet to one that was low in saturated fat and with a high ratio of polyunsaturated to saturated fatty acids was undoubtedly the mog difficult aspect of the dietary experiment.

\section{STATISTICAL METHODS}

The significance of the differences in mean total cholesterol concentration and low density lipoprotein cholesterol concentration between the particis pants when they were eating two eggs and when they were eating seven eggs was assessed by Student's $t$ test. Logarithmically transformed data wese used. The mean differences after four and eight weeks of eating two or seven eggs and the $95 \%$ confidence intervals were also calculated. ${ }^{25}$

Two approaches were used to determine whether there were any participants whose plasma cholesterol concentration was particularly seff sitive to increases in dietary cholesterol. Firstly, the histograms of individua differences at the end of the periods of eating two eggs a week and seven eggs a week were examined for skewness, and, secondly, the prevalence off hyperresponders and hyporesponders was compared as suggested Bronsgeest-Schoute et al, ${ }^{5}$ Katan and Beynen, ${ }^{6}$ and $\mathrm{Oh}$ and Miller. ${ }^{7}$ In o ${ }^{\circ}$ calculations cholesterol concentrations that were more than two SD on either side of the mean were regarded as a hyporesponse or hyperresponse.

\section{Results}

Table II shows the mean total cholesterol concentrations and low densi lipoprotein cholesterol concentrations and table III the mean differences akd $95 \%$ confidence intervals. After four and eight weeks there were no significant differences in the mean concentrations between the two egg and seven egg periods for patients attending the lipid clinic. This was true for the whole group of patients and for the patients who had familial hypepcholesterolaemia, who were examined separately because of the possibility that their response might differ from that of the other patients. In the groषp of healthy volunteers there were significant differences in the total cholesterol concentrations at the end of four weeks. Both the tooil cholesterol and low density lipoprotein cholesterol concentrations of the combined patients and subjects also differed significantly at the end of the four weeks. At the end of eight weeks, however, there were no significant differences in total cholesterol and low density lipoprotein cholestemo concentrations in the patients from the lipid clinic, in the healthy volunteers, or in both groups combined, and the variance about the mean was similar. There were no significant differences in high density lipoprotein cholesteध or plasma triglyceride concentrations at four or eight weeks.

TABLE I-Composition of 1500 kcal diet indicating difference in cholesterol intake during the two experimental periods

\begin{tabular}{|c|c|c|c|c|c|c|c|c|}
\hline & \multirow[b]{2}{*}{$\begin{array}{c}\text { Energy intake } \\
\text { (kcals) }\end{array}$} & \multicolumn{3}{|c|}{$\%$ Energy } & \multirow{2}{*}{$\begin{array}{l}\text { Polyunsaturated: } \\
\text { saturated } \\
\text { fatty acids }\end{array}$} & \multicolumn{2}{|c|}{ Cholesterol (mg/day) } & \multirow{2}{*}{ Fibre (g/day) } \\
\hline & & Protein & Carbohydrate & Total fat & & $\begin{array}{l}\text { Seven eggs/ } \\
\text { week }\end{array}$ & $\begin{array}{l}\text { Two eggs/ } \\
\text { week }\end{array}$ & \\
\hline $\begin{array}{l}\text { Hyperlipidaemic patients } \\
\text { Healthy volunteers }\end{array}$ & $\begin{array}{l}1500 \\
1500\end{array}$ & $\begin{array}{l}18 \\
15\end{array}$ & $\begin{array}{l}56 \\
50\end{array}$ & $\begin{array}{l}26 \\
35\end{array}$ & $\begin{array}{l}0.8 \\
0.6\end{array}$ & $\begin{array}{l}308 \\
350\end{array}$ & $\begin{array}{l}120 \\
150\end{array}$ & $\begin{array}{l}41 \\
33\end{array}$ \\
\hline
\end{tabular}


TABLE II-Mean concentrations ${ }^{\star}$ of total and low density lipoprotein cholesterol during study

\begin{tabular}{|c|c|c|c|c|c|c|}
\hline & \multicolumn{3}{|c|}{ Mean (SEM) total cholesterol concentration (mmol/l) } & \multicolumn{3}{|c|}{ Mean (SEM) low density lipoprotein cholesterol concentration (mmol/l) } \\
\hline & $\begin{array}{c}\text { Treated hyperlipidaemic } \\
\text { patients } \\
(n=33)\end{array}$ & $\begin{array}{l}\text { Normolipidaemic } \\
\text { subjects } \\
(n=135)\end{array}$ & $\begin{array}{l}\text { Total group } \\
(n=168)\end{array}$ & $\begin{array}{c}\text { Treated hyperlipidaemic } \\
\text { patients } \\
(\mathrm{n}=33)\end{array}$ & $\begin{array}{c}\text { Normolipidaemic } \\
\text { subjects } \\
(n=135)\end{array}$ & $\begin{array}{l}\text { Total group } \\
(n=168)\end{array}$ \\
\hline $\begin{array}{l}\text { Initial pretreatment } \\
\text { After four weeks: }\end{array}$ & $6.83(0.03)$ & $5.45(0.02)$ & $5 \cdot 70(0 \cdot 02)$ & $4 \cdot 69(0.04)$ & $3.35(0.03)$ & $3.57(0.02)$ \\
\hline $\begin{array}{l}\text { Of eating seven eggs } \\
\text { Of eating two eggs } \\
\text { After eight weeks: }\end{array}$ & $\begin{array}{l}6.78(0.03) \\
6.72(0.05)\end{array}$ & $\left.\begin{array}{l}5.32(0.02) \\
5.17(0.02)\end{array}\right\} \dagger$ & $\left.\begin{array}{l}5.57(0.02) \\
5.43(0.02)\end{array}\right\} †$ & $\begin{array}{l}4.68(0.05) \\
4.59(0.05)\end{array}$ & $\begin{array}{l}3.20(0.03) \\
3.07(0.03)\end{array}$ & $\left.\begin{array}{l}3.43(0.03) \\
3.31(0.03)\end{array}\right\} \dagger$ \\
\hline $\begin{array}{l}\text { Of eating seven eggs } \\
\text { Of eating two eggs }\end{array}$ & $\begin{array}{l}6.66(0.03) \\
6.52(0.04)\end{array}$ & $\begin{array}{l}5.33(0.02) \\
5.23(0.02)\end{array}$ & $\begin{array}{l}5.57(0.02) \\
5.46(0.02)\end{array}$ & $\begin{array}{l}4.68(0.05) \\
4.63(0.05)\end{array}$ & $\begin{array}{l}3.15(0.05) \\
3.03(0.03)\end{array}$ & $\begin{array}{l}3.41(0.03) \\
3.30(0.03)\end{array}$ \\
\hline
\end{tabular}

${ }^{\star}$ Mean concentrations of $\log$ transformed data.

tp<0.05, Student's paired $t$ test.

TABLE III-Mean difference (95\% confidence interval) in total and low density lipoprotein cholesterol concentration between patients eating two eggs a week and those eating seven eggs after four and eight weeks

\begin{tabular}{|c|c|c|c|c|c|c|}
\hline & \multicolumn{3}{|c|}{ Mean difference in total cholesterol concentration $(\mathrm{mmol} / \mathrm{l})$} & \multicolumn{3}{|c|}{ Mean difference in low density lipoprotein cholesterol concentration $(\mathrm{mmol} / \mathrm{l})$} \\
\hline & $\begin{array}{c}\text { Treated hyperlipidaemic } \\
\text { patients } \\
(n=33)\end{array}$ & $\begin{array}{c}\text { Normolipidaemic } \\
\text { subjects } \\
(n=135)\end{array}$ & $\begin{array}{l}\text { Total group } \\
(n=168)\end{array}$ & $\begin{array}{c}\text { Treated hyperlipidaemic } \\
\text { patients } \\
(n=33)\end{array}$ & $\begin{array}{c}\text { Normolipidaemic } \\
\text { subjects } \\
(n=135)\end{array}$ & $\begin{array}{l}\text { Total group } \\
(\mathrm{n}=168)\end{array}$ \\
\hline After four weeks & $\begin{array}{c}0.05 \\
(-0.25 \text { to } 0.36)\end{array}$ & $\begin{array}{l}0 \cdot 15 \\
(0.04 \text { to } 0 \cdot 26)\end{array}$ & $\begin{array}{c}0.13 \\
(0.03 \text { to } 0.23)\end{array}$ & $\begin{array}{c}0.06 \\
(-0.18 \text { to } 0.31)\end{array}$ & $0 \cdot 12$ & $0 \cdot 11$ \\
\hline After eight weeks & $\begin{array}{c}0.13 \\
(-0.11 \text { to } 0.37)\end{array}$ & $\begin{array}{c}0.12 \\
(0 \text { to } 0 \cdot 24)\end{array}$ & $\begin{array}{c}0.12 \\
(0 \text { to } 0.23)\end{array}$ & $\begin{array}{c}0.06 \\
(-0.16 \text { to } 0.27)\end{array}$ & $\begin{array}{c}0 \cdot 13 \\
(0 \text { to } 0 \cdot 26)\end{array}$ & $\begin{array}{c}0.12 \\
(0 \text { to } 0.23)\end{array}$ \\
\hline
\end{tabular}

^ Confidence intervals not calculated because of skewed distribution.

TABLE IV-Prevalence of changes in low density lipoprotein cholesterol concentration after four weeks

\begin{tabular}{|c|c|c|c|c|c|c|c|c|c|c|c|c|c|c|c|c|}
\hline $\begin{array}{l}\text { Change (mmol/l): } \\
\text { Prevalence: }\end{array}$ & $-\frac{1 \cdot 3}{2}$ & $-\frac{1 \cdot 2}{2}$ & $-1 \cdot 1$ & $-1 \cdot 0$ & $\begin{array}{c}-0.9 \\
3\end{array}$ & $\begin{array}{c}-0 \cdot 8 \\
5\end{array}$ & $\begin{array}{c}-0 \cdot 7 \\
1\end{array}$ & $\begin{array}{c}-0.6 \\
9\end{array}$ & $\begin{array}{c}-0 \cdot 5 \\
3\end{array}$ & $\begin{array}{c}-0 \cdot 4 \\
10\end{array}$ & $\begin{array}{c}-0.3 \\
6\end{array}$ & $\begin{array}{c}-0 \cdot 2 \\
3\end{array}$ & $\begin{array}{c}-0 \cdot 1 \\
13\end{array}$ & $\begin{array}{l}0 \\
9\end{array}$ & $\begin{array}{c}+0 \cdot 1 \\
10\end{array}$ & $\begin{array}{c}+0 \cdot 2 \\
10\end{array}$ \\
\hline $\begin{array}{l}\text { Change (mmol/l): } \\
\text { Prevalence: }\end{array}$ & $\begin{array}{c}+0 \cdot 3 \\
12\end{array}$ & $\begin{array}{c}+0.4 \\
9\end{array}$ & $\begin{array}{c}+0.5 \\
8\end{array}$ & $\begin{array}{c}+0.6 \\
1\end{array}$ & $\begin{array}{c}+0.7 \\
6\end{array}$ & $\begin{array}{c}+0 \cdot 8 \\
12\end{array}$ & $\begin{array}{c}+0.9 \\
3\end{array}$ & $+\frac{1}{5} \cdot 0$ & $+1 \cdot 1$ & $+1 \cdot 4$ & +1.5 & $+\frac{1 \cdot 6}{2}$ & $+1 \cdot 7$ & $+2 \cdot 2$ & $\begin{array}{c}+2 \cdot 7 \\
1\end{array}$ & \\
\hline
\end{tabular}

The total cholesterol concentration of individual participants varied in response to the ingestion of seven eggs a week compared with two eggs a week by $-21 \%$ to $+44 \%$ after four weeks and by $-23 \%$ to $+49 \%$ after eight weeks. Further analysis, however, produced no evidence for a group of hyperresponders at the end of eight weeks of eating seven eggs. Histograms of the differences in total cholesterol and low density lipoprotein cholesterol concentrations of participants after eating two and seven eggs a week were plotted. The differences in total cholesterol concentration were not significantly skewed in any group at any time. At the end of four weeks the differences in low density lipoprotein cholesterol concentrations were significantly skewed in the normolipidaemic subjects (coefficient of skewness $\mathrm{g}_{1}=2 \cdot 38$ ) and in the whole group $\left(\mathrm{g}_{1}=2 \cdot 11\right.$, table IV), but after eight weeks this skewness was no longer apparent in either the normolipidaemic subjects or the whole group. The differences in the hyperlipidaemic subjects were not significantly skewed at any time.

\section{Discussion}

A reduction in the total and saturated fat intake reduces the plasma concentration of total cholesterol and low density lipoprotein cholesterol and forms the cornerstone of national dietary recommendations aimed at lowering the risk of coronary heart disease. Most dietary recommendations also include advice to increase the ratio of polyunsaturated to saturated fatty acids to reduce further the total cholesterol and low density lipoprotein cholesterol concentrations. ${ }^{26}{ }^{27}$ These changes may also modify haemostatic variables known to be associated with coronary heart disease. ${ }^{28}$

The relation between dietary cholesterol and total plasma cholesterol concentration is less clear. Reducing saturated fat in the diet usually reduces cholesterol intake, but advice concerning a further reduction in dietary cholesterol is a particularly controversial feature of current dietary recommendations. The suggestion that dietary cholesterol should be restricted is based on two premises. The first, based on the Keys formula ${ }^{4}$ and several other feeding experiments, is that decreasing dietary cholesterol will decrease serum cholesterol concentration. The second is that there is a small population of hyperresponders whose serum cholesterol concentration rises significantly with small increases in cholesterol from food. There are, however, difficulties associated both with the interpretation of the formula and feeding studies and with the definition of hyperresponse.

The Keys formula ${ }^{4}$ is a mathematical method of predicting change in plasma cholesterol concentration as a result of dietary change. With this formula the predicted increase in total cholesterol concentration in patients eating seven eggs a week compared with two is $0.2 \mathrm{mmol} / \mathrm{l}$. After eight weeks we found a mean difference of $0.1 \mathrm{mmol} / 1(95 \%$ confidence interval 0 to $0 \cdot 23)$.

Where this formula has been used to predict change, modifying the intake of dietary cholesterol has usually resulted in a greater change of both predicted and observed cholesterol concentrations. Earlier investigations, however, did not include studies of the effects of dietary cholesterol taken as part of a diet in which several other features were capable of lowering cholesterol concentration (low saturated fat intake, increased ratio of polyunsaturated to saturated fatty acids, high fibre intake). Most have been carried out in subjects consuming a background diet with an appreciably higher fat content than that currently recommended, and extreme quantities of dietary cholesterol have been contrasted. The present study was designed to investigate the effects on plasma cholesterol concentrations of a contrast between people eating two and seven eggs a week and otherwise following a diet low in saturated fat, with 
a modest increase in the ratio of polyunsaturated to saturated fatty acids, and high in dietary fibre. The contrast was intended to provide the basis for practical recommendations and entailed comparing the results of halving and almost doubling the present national average egg intake. The findings suggest that if the current nutritional guidelines are followed there is neglible additional benefit to be gained from restricting the intake of eggs and little disadvantage in a modest increase.

The results of this investigation also underline the importance of longer term studies. After four weeks we noted a small but significant difference in the total plasma cholesterol concentration in the healthy volunteers and in the total cholesterol and low density lipoprotein cholesterol concentrations in the whole group; these differences were no longer evident after eight weeks of follow up. Short term changes, reflecting a transient response with insufficient time for metabolic adaptation, have occurred after other dietary changes-for example, temporary hypertriglyceridaemia after a change to a high carbohydrate diet $^{29}$ - and should not form the basis of dietary recommendations. The duration of the study may also explain why we have been unable to define clearly a population of hyperresponders. The skewed distribution of differences in total cholesterol and low density lipoprotein cholesterol concentrations between the two egg and seven egg periods, seen after four weeks but not after eight weeks, suggests that hyperresponse may be temporary. Most studies have not attempted to define hyperresponse, so it is difficult to compare data.

Our data do not exclude the possibility that dietary cholesterol may have a greater influence on the serum cholesterol concentration when fed as part of a diet high in saturated fat or when more extreme intakes are compared; nor do they exclude the occurrence of hyperresponse under such circumstances. Dietary cholesterol in substantial quantities may influence the composition of the intermediate density lipoproteins with atherogenic potential. Connor et al have suggested a cholesterol/saturated fat index for calculating the hypercholesterolaemic-atherogenic potential of food..$^{30}$ Our findings suggest that the cholesterol/saturated fat index may not be helpful in determining foods with a high atherogenic potential when they are taken as part of a low fat diet: two eggs have a cholesterol/saturated fat index of 29 whereas $100 \mathrm{~g}$ of high fat meat has a value of 18 . Calculation of the cholesterol/saturated fat index is based largely on the cholesterol content of the food. In the present recommendations, in which cholesterol intake has already been reduced by decreasing saturated fat intake, there seems little to be gained by further emphasising reductions in the intake of foods high in cholesterol such as eggs.

We thank all our volunteers for their enthusiastic and dedicated participation; Dr Klim McPherson for statistical advice; Mrs S Gerring and others for taking blood; Mrs M Thorogood for help and encouragement; and Mrs A Reeve for typing the manuscript.

\section{References}

1 Roberts SL, McMurray MP, Connor WE. Does egg feeding (i.e. dietary cholesterol) affect plasm cholesterol levels in humans? The results of a double blind study. Am f Clin Nutr 1981;3

2 Sacks FM, Miller L, Sutherland M, et al. Ingestion of egg raises plasma low density lipoproteinsèn free-living subjects. Lancet 1984;i:647-9.

3 Mistry P, Miller NE, Laker M, Hazzard WR, Lewis B. Individual variation in the effects dietary cholesterol on plasma lipoproteins and cellular homeostasis in man. Studies of LDE receptor activity and 3-hydroxy-3-methylglutaryl coenzyme A reductase activity in blood mononuclear cells. I Clin Invest 1981;67:493-502.

4 Keys A, Anderson JT, Grande F. Serum cholesterol response to changes in diet. II. The effect 6 F cholesterol in the diet. Metabolism 1965;14:59-65.

5 Bronsgeest-Schoute DC, Hermus RJJ, Dallinga-Thie GM, et al. Dependence of the effects dietary cholesterol and experimental conditions on serum lipids in man. III. The effect ón serum cholesterol of removal of eggs from the diet of free-living habitually egg-eating peop Am $\mathcal{J}$ Clin Nutr 1979;32:2193-7.

$6 \mathrm{Katan}$ MB, Beynen AC. Hyper-response to dietary cholesterol in man. Lancet 1983;i:1213. Oh SY, Miller LT. Effect of dietary egg on variability of plasma cholesterol levels and lipoprotein cholesterol. Am f Clin Nutr 1985;42:421-31.

8 National Institutes of Health consensus development conference statement. Lowering blo cholesterol to prevent heart disease. Washington, DC: United States Department of Health and Human Services, 1985:5-7.

9 Blackburn H. Diet and mass hyperlipidaemia. A public health view. In: Levy RI, Rifkind BM, Dennis BH, Ernst ND, eds. Nutrition, lipids and coronary heart disease: a global view. New York: Raven Press, 1979:309-47.

10 Mayer GA, Ford Connell W, De Wolfe MS, Beveridge JMR. Diet and plasma cholesterol levels, Am $\mathcal{F}$ Clin Nutr 1954;2:316-21.

11 Nestel PJ, Poyser A. Changes in cholesterol synthesis and excretion when cholesterol intakecia increased. Metabolism 1976;25:1591-9.

12 Schonfeld G, Patsch W, Rudel LL, et al. Effects of dietary cholesterol and fatty acids on plasro lipoproteins. $\mathcal{F}$ Clin Invest 1982;69:1072-80.

13 Bronsgeest-Schoute DC, Hautvast JGAJ, Hermus RJJ. Dependence of the effects of dietain cholesterol and experimental conditions on serum lipids in man. I. Effects of dietary cholestefs in a linoleic acid-rich diet. Am $\mathcal{F}$ Clin Nutr 1979;32:2183-7.

14 Beynen AC, Katan MB. Reproducibility of the variations between humans in the response serum cholesterol to cessation of egg consumption. Atherosclerosis 1985;57:19-31.

15 Nestel PJ, Havenstein N, Homma Y, Scott TW, Cook LJ. Increased sterol excretion wffP pel PJ, Haved polyunsaturated fat, high-cholesterol diets. Metabolism 1975;24:189-98.
16 Ministry of Agriculture, Fisheries and Food. Household food consumption and expenditure: 19 d्छ

Anmual report of the National Survey Committee. London: HMSO, 1985.
17 Committee on Medical Aspects of Food Policy. Diet and cardiovascular disease. London: HMS@ 1984. 1984.

18 Seidel J, Schlumberger $\mathrm{H}$, Klose $\mathrm{S}$, et al. Improved reagent for the enzymatic determination of serum cholesterol. F Clin Chem 1981;19:838-9.

19 Staehler F, Gruber W, Stinshoff K, Raeschlau P. Practical enzymic cholesterol determination Medizimische Laboratorium 1977;30(2):29-37.

20 Trinder $P$. Determination of glucose in blood using glucose oxidase with an alternative oxyge acceptor. Ann Clin Biochem 1969;6:24-7.

21 Burstein M, Scholnick HR, Morfin R. Rapid method for the isolation of lipoproteins from humgृ serum by precipitation with polyanions. I Lipid Res 1970;11:583-95.

22 Ononogbu IC, Lewis B. Lipoprotein fractionation by a precipitation method. A simpte quantitative procedure. Clin Chim Acta 1976;71:397-402.

23 Wahlefeld AW. Triglycerides. Determination after enzymatic hydrolysis. In: Bergmeyer HU, \& Methods of enzymatic analysis. New York and London: Verlag Chemie Weinheim and Acadensc Mress, 1974: 1831 .

24 Moore RA, Oppert S, Eaton P, Mann JI. Triglyceride fatty acids confirm a change in dietary Clin Endocrinol (Oxf 1977;7:143-9.

25 Bailey NTJ. Statistical methods in biology. 2nd ed. London: Hodder and Stoughton, 1981

26 Lewis B. Dietary prevention of ischaemic heart disease-a policy for the ' 80 's. Br MedO 1980;281:177-80.

27 Lewis B, Katan M, Merkx I, et al. Towards an improved lipid-lowering diet: additive effects changes in nutrient intake. Lancet $1981 ;$ ii:1310-3.

28 Simpson HCR, Mann JI, Chakrabarti R, et al. Effect of high-fibre diet on haemostatic variables diabetes. BrMed $\mathcal{F}$ 1982;284:1608.

29 Antonis A, Bersohn I. The influence of diet on serum triglycerides in South African and Bantit

prisoners. Lancet $1961 ; \mathrm{i}: 3-9$.
30 Connor SL, Gustafson JR, Artaud-Wild SM, et al. The cholesterol/saturated-fat index: indication of the hypercholesterolaemic and atherogenic potential of food. Lancet 1986): 1229-32.

(Accepted 28 November 1986)

. 